\title{
Ethnography of Emerging Translocated Virtual Student Communities in Kenya
}

\author{
Egesah Omar Badiru
}

Department of Anthropology and Human Ecology, Moi University, Kenya

Copyright $@ 2019$ by authors, all rights reserved. Authors agree that this article remains permanently open access under the terms of the Creative Commons Attribution License 4.0 International License

\begin{abstract}
Internet based technologies and electronic devices have changed the way we look at the world in the $21^{\text {st }}$ Century and especially among the savvy youth. This position is ever changing speedily, and has greatly influenced the way we communicate, pre-occupy ourselves, and concentrate at work, in class and even during special moments reserved for other engagements of life. Young persons were surveyed from Moi and Kisii University about their spatial occupation of two worlds; the real world and the virtual space. University students are experiencing new forms of interaction and social relations, more with the cyber world, that transform the very meaning of life experiences including education and knowledge, as a result of duality dwelling in the real world and the virtual space. University students revealed how learning occurs in multiple contexts, and many a times beyond the classroom. This answers the question how students learn inside and outside the lecture room from their relationship with the cyber space world. Profoundly, the paper presents the experiences and felt outcomes of dwelling in binary worlds and recommends the benefits of translocating in binary spaces and need to research characteristics of the youth who pilgrimage and operate in these newer community spaces.
\end{abstract}

Keywords Ethnography, Students, Internet, Virtual Space, Translocate, Learning

\section{Introduction}

Current web based technologies as well as demands of life to undertake multiple tasks and actions at the same time point to a fundamental: the relationship between people and the spaces they live in is fast transforming, especially among the youth. There are traditional uses of space and the emerging refiguration of space in the first changing $21^{\text {st }}$ Century that is driven by the internet and telephone and computer technology[1]. This in itself is fast manifesting as transformation of the social order [2] among the youth who are cyber technology savvy. The youth are studied in their two translocalised spaces defined by the real activity space they reside in concurrently with the virtual internet space they translocate in. Technologies and electronic devices are nowadays developing faster than we had ever imagined[4], and they have begun to change the ways we communicate, teach, learn and investigate and most critical to this paper, the way the youth preoccupy themselves in real and virtual spaces of their daily lives. University students are experiencing new forms of interaction and social relations, what transforms the very meaning of education, knowledge, learning [5] and relating to other needs. For one, university learning is now taking place in multiple contexts [4], and many of them happen beyond the lecture room, even during the lecture or not. The overall objective of this paper is to understand the ethnography of an emerging translocalised community of university students residing both in real and virtual binary spaces. Three research questions are answered by the paper; first how university students learn within the boarder that connects the lecture room with their daily cyber space lives; second what are the phenomenological ethnographic experiences of residing in binary spaces; third, what benefits and detriments are felt translocating between two spaces.

The reflections of the paper are built and framed from a survey of 384 [3] university students in Moi and Kisii University using a semi-structured questionnaire and observations between 2017 - 2018. The loci of the paper is to explain how technologies and electronic devices are developing faster than we had ever imagined, and they have begun to change the ways educated youth learn, and attach to the realities of their lives by perpetual interrelationship using the cyber space. This paper is ethnographic because it departs from the traditions of building ethnographies $[6,8]$ of physical communities to study education and lives of a transforming virtual community of university students. Embedded in multiple cultures, university students pilgrimage between two scenarios that define their education on one hand and self-learning and social interaction on the other hand thus forming new forms of interactions, social relations and 
identities that are portrayed in multiply ways. This in fact could be slowly transforming the very meaning of what we conventionally understand by university education and social interaction. Today learning at the university occurs in multiple contexts, and as it is shown by different studies below, many of these learning scenes emerge beyond the lecture room $[4,5]$. In these new spaces, a scenario is formed where young people begin to dialogue with multiple languages inhabiting a space where technological devices are commonplace, and as and where to exit -to be visible- -is synonymous of residing at fractal environments and social networks.

Cohabiting in these 'dislocated' cultures[11], or what scholars refer to as 'hybrid' [12] university students begin to deploy learning experiences that go far beyond of what is prescribed by the curriculum and course outlines, as also explained elsewhere [13]. Inhabiting in the borders that connect the inside and the outside of the lecture room, he students develop enough skills to wander between the two dislocated communities. From the interviews, students thus manifest that using their phones, computers and the internet, they have learned; to search for information; to create and send social messages; to share multimedia content; and in some cases, to learn other ways to learn. Therefore, this paper reports these experiences and ponders over the question; what are the benefits of these experiences and again, how detrimental are the experiences of shuttling to the student, their immediate environments and their university education goals?

In this description, we are able to understand the various ways in which new generations of students relate to knowledge at the same time relating to the world that they live in from their relationship with the technological devices. The inquiry presented here aims to understand from the interview narratives [7] and observations of university students, how the current generations have gestated different learning experiences and forms of social relationships with their world using technological devices. The paper observes how this relationship has worked in the construction of different skills, knowledge and experiences lived in the area of translocation between the lecture room and students' daily lives. These experiences enable us to imagine and observe clues of an adaptive fast changing generation that reside in two different worlds at the same time. This could be an opportunity then to analyse turning points in the lives of these young people and their experiences with technologies of the $21^{\text {st }}$ Century. We could also be hinting to multiple sources of learning at universities, in the contemporary world. Anthropologically speaking, the paper exponentially espouses new emerging ethnographies $[6,7,8,9]$, of virtual communities and it will be interesting in future to study these emerging communities holistically to determine if they are really transiting to cyber spaces or they remain living a hybrid life.

\section{Materials and Methods}

In the history of social research each ethnography inquiry when it begins requires in a certain sense of the researcher imagination to reinvent the methodology. A reinvention that perhaps has to do with the nature of the method, as described by, Geertz we speak of an "informal logic of real life"[14, 15], as ethnographies are based on the realities of life of others $[7,8,9]$. Following this line, we start from two assumptions; the first one is that each one is a unique ethnography. The second one is that the problems we meet with ethnographies are not only for the ethnographical method, [10] but are problems of the social research as a whole.

The research described here is ethnographic cyber anthropology that studies communities of internet dwelling university students, but descriptive and cross-sectional in design and it relied on a mixed methods methodology. The methodological design took into account the knowledge base of university students and their technological acumen. This approach helped in generating data on experiences of telephone and internet use both from male and female students from two universities. Moi University $(53,000)$ and Kisii University, Eldoret Campus $(4,000)$ undergraduate students formed the population of study. Despite specificity of the population of study, findings of this study epitomize but cannot be generalizable to the $21^{\text {st }}$ Century university students around the world, despite the fact that they share the common tools of technology and knowledge generation.

\subsection{Sampling}

Using the Morgan and Krejcie (1970) [3], formula for sample estimation, 384 students were sampled using stratified simple random sampling for questionnaire administration by university, gender and year of study. In addition, 26 observations were made, 13 of Moi university students and 13 of Kisii University students, using internet on phone at lectures and outside lectures for knowledge generation and social interaction. These details are summarized in the table below: 
Table 1. Methods of data collection and sample size

\begin{tabular}{|c|c|c|c|}
\hline Two universities & Data source & $\begin{array}{c}\text { Sample sizes per group } \\
\text { (MU \& KSU) }\end{array}$ & Total \\
\hline \multirow[t]{2}{*}{$\begin{array}{l}\text { Moi University \& } \\
\text { Kisii University }\end{array}$} & $\begin{array}{ll}\text { Questionnaire } \\
\text { (Krejcie\& Morgan (1970), } \\
\text { confidence = 95\%). 94\% Response Rate } \\
\text { (361 of 384) }\end{array}$ & 192 & $\begin{array}{c}361 \\
(384)\end{array}$ \\
\hline & Observation & $13+13$ & 26 \\
\hline \multicolumn{4}{|c|}{$\begin{array}{l}\text { Sampling Procedures: } \\
\text { Questionnaire: Stratified by university and year of study; simple random, including both sexes } \\
\text { Observation: Purposive, direct and disguised based on phenomenon observed }\end{array}$} \\
\hline
\end{tabular}

\subsection{Data Collection}

a) Questionnaire: The quantitative tool was administered to a sample of 384 respondents enlisted from the students' population, to determine telephone internet use for learning and for social communication. The tool was administered to elicit perspectives of use, forms of use, types of information obtained from the internet, perceptions of lecture and non-lecture learning, learning contexts, social interactions, their times and nature. This tool was therefore, used to draw information from students about the practices and experiences using the internet on telephone devices. The tool was semi-structured to obtain some narrations of experiences.

b) Observation- Researchers who interviewed students were trained and experienced qualitative researchers and they went on further to directly observe internet phone use between two scenes of lecture and social use environments, to mark out translocation and purpose of use at any given times. Twenty such observations were disguised to capture the real situation, yet six were direct obtrusive observations to ascertain the interview information. In the twenty, researchers retreated to record using their own phones, what they had freshly observed and even took pictures of occurrences.

\subsection{Data Analysis}

The questionnaire provided quantitative data which was fed in SPSS version 23.0 for both descriptive and inferential analysis of internet phone use between two scenes of lecture and social use environments. There were no much variations of the phenomena under study in both universities and by gender and year of study to warrant comparisons and contrasts. This means that internet phone use between two scenes of lecture and social use environments commonly applies among university students in the two universities. Generally the analysis determined if where one was determined what information they retrieved or deciphered using the phone connected to the internet. Data from observations were retrieved from phone memories and saved as MS word transcript files of each distinct observation. Data were then coded inductively through a repeated series of reading over each transcript. What followed was collapsing of the 26 transcripts into one master roll, ending up with information on each theme categorized and collated together on the master document. This was followed by careful synthesis and back and forth interpretation of information on each theme and extraction of write ups on the theme. Observation pictures were brought in to support the write ups. Using the Philip Mayring tradition [16], this ended up with content analysis applying constant comparative meaning oriented analysis. The data was analysed to observe what happens when university students transit across various spaces: everyday environment $<>$ lecturer room $<>$ virtual space $<>$ personal space.

\subsection{Ethical Consideration and Institutional Affiliation}

Telephone and internet use is private and the researchers had to follow all codes of ethics and applied the three principles of research ethics; beneficence, respect and justice as prescribed in the Belmont Report [17], to the fullest use, to ensure prudent ethics of research are followed. Affiliation to Moi University, and teaching relationships with Kisii University eased rapport, reconnaissance and consenting processes. The final research protocols were endorsed by the Moi University Institutional Research and Ethics Review Board (IREC) for ethical approval. On the ground, all participants unless during disguised observations, were consented before participation in the study and through university administration students were notified about the research.

In summary, the study combined three different field work oriented methods: ethnographic observation $[14,18$, 19, 20, 21], and virtual ethnography [22], plus personal interviews and reflexive field notes. Into this approach, the methods successfully mined data on a new phenomenon using traditional Anthropological methods, to analyse university students' virtual worlds through having access to some of the digital environments and technologies they use inside and outside the university.

\section{Findings}

The overall objective of this paper is to understand the ethnography of an emerging translocalised community of university students residing both in real and virtual binary 
spaces. Three research questions are answered by the paper; first how university students learn within the boarder that connects the lecture room with their daily cyber space lives; second what are the phenomenological ethnographic experiences of residing in binary spaces; third, what benefits and detriments are felt translocating between two spaces. Ordinal scale variables were studied using scores on scale of: 1=very low; 2=low; 3=average; 4=high; 5=very high.

Using ethnography to investigate the ways in which internet use becomes socially significant for learning outside the lecture room reveals a lot about telephone and internet use by university students. More male students (54.3\%), than female students (45.7\%), participated in the study.

Table 2. Gender

\begin{tabular}{|c|c|c|c|c|}
\hline \multicolumn{2}{|c|}{} & \multicolumn{2}{|c|}{ University } & \multirow{2}{*}{ Total } \\
\cline { 3 - 4 } \multicolumn{2}{|c|}{} & Moi & Kisii & \\
\hline \multirow{2}{*}{ Male } & Count & 116 & 80 & 196 \\
\cline { 2 - 5 } & \% within University & $57.7 \%$ & $50.0 \%$ & $54.3 \%$ \\
\hline \multirow{2}{*}{ Female } & Count & 85 & 80 & 165 \\
\cline { 2 - 4 } & \% within University & $42.3 \%$ & $50.0 \%$ & $45.7 \%$ \\
\hline Total & University & 201 & 160 & 361 \\
\hline
\end{tabular}

\subsection{Use of the Internet to Learn}

University students (59.0\%) use the internet by their smart phones to learn and access knowledge beyond the learning they acquire in the lecture rooms. This means that the lecture room space and environment is not where they reside alone, with respect to knowledge acquisition through learning. They move between more than one spaces to acquire knowledge.
Table 3. Do you use telephone internet to learn and access knowledge besides lecture room knowledge

\begin{tabular}{|c|c|c|c|c|}
\hline \multicolumn{2}{|c|}{} & \multicolumn{2}{|c|}{ University } & \multirow{2}{*}{ Total } \\
\cline { 3 - 4 } \multicolumn{2}{|c|}{} & Moi & Kisii & \\
\hline \multirow{2}{*}{ Yes } & Count & 119 & 94 & 213 \\
\cline { 2 - 5 } & \% within University & $59.2 \%$ & $58.8 \%$ & $59.0 \%$ \\
\hline \multirow{2}{*}{ No } & Count & 82 & 66 & 148 \\
\cline { 2 - 5 } & \% within University & $40.8 \%$ & $41.2 \%$ & $41.0 \%$ \\
\hline \multirow{2}{*}{ Total } & Count & 201 & 160 & 361 \\
\cline { 2 - 5 } & \% University & $100.0 \%$ & $100.0 \%$ & $100.0 \%$ \\
\hline
\end{tabular}

\subsection{Complementation of Lecture Room and Internet Learning}

Table 4. To what extent does internet learning complement lecture room learning

\begin{tabular}{|c|c|c|c|c|}
\hline \multirow{2}{*}{\multicolumn{2}{|c|}{}} & \multicolumn{2}{|c|}{ University } & \multirow{2}{*}{ Total } \\
\cline { 2 - 5 } & Count & 15 & 43 & 58 \\
\hline \multirow{3}{*}{ Very low } & \% within University & $7.5 \%$ & $26.9 \%$ & $16.1 \%$ \\
\cline { 2 - 5 } & Count & 14 & 23 & 37 \\
\cline { 2 - 5 } & \% within University & $7.0 \%$ & $14.4 \%$ & $10.2 \%$ \\
\hline \multirow{2}{*}{ Low } & Count & 38 & 50 & 88 \\
\hline \multirow{2}{*}{ Average } & \% within University & $18.9 \%$ & $31.2 \%$ & $24.4 \%$ \\
\hline \multirow{2}{*}{ High } & Count & 55 & 7 & 62 \\
\cline { 2 - 5 } & \% within University & $27.4 \%$ & $4.4 \%$ & $17.2 \%$ \\
\hline \multirow{2}{*}{ Very high } & Count & 79 & 37 & 116 \\
\cline { 2 - 5 } & \% within University & $39.3 \%$ & $23.1 \%$ & $32.1 \%$ \\
\hline \multirow{2}{*}{ Total } & Count & 201 & 160 & 361 \\
\cline { 2 - 5 } & \% University & $100.0 \%$ & $100.0 \%$ & $100.0 \%$ \\
\hline
\end{tabular}

Use of the internet to learn, highly complements lecture room learning, which affirms the conviction of the finding that university students do not pitch in one space for learning, but move from one space to another for their learning needs. 
Table 5. What aspects do you commonly use the phone internet for

\begin{tabular}{|c|c|c|c|c|c|c|c|c|}
\hline & & & \multicolumn{6}{|c|}{ Scale } \\
\hline Aspects & County & & Very low & Low & Average & High & Very high & Total \\
\hline \multirow{6}{*}{ Specialization Course content } & \multirow{2}{*}{ Moi } & Count & 16 & 15 & 29 & 53 & 88 & 201 \\
\hline & & $\%$ & 8.0 & 7.5 & 14.4 & 26.4 & 43.8 & 100.00 \\
\hline & \multirow{2}{*}{ Kisii } & Count & 12 & 17 & 25 & 61 & 45 & 160 \\
\hline & & $\%$ & 7.5 & 10.6 & 15.6 & 38.1 & 28.1 & 100.00 \\
\hline & \multirow{2}{*}{ Total } & Count & 28 & 32 & 54 & 114 & 133 & 361 \\
\hline & & $\%$ & 7.8 & 8.9 & 15.0 & 31.6 & 36.8 & 100.00 \\
\hline \multirow{6}{*}{ Content for other/ elective courses } & \multirow{2}{*}{ Moi } & Count & 49 & 29 & 42 & 31 & 50 & 201 \\
\hline & & $\%$ & 24.4 & 14.4 & 20.9 & 15.4 & 24.9 & 100.00 \\
\hline & \multirow{2}{*}{ Kisii } & Count & 41 & 27 & 62 & 5 & 25 & 160 \\
\hline & & $\%$ & 25.6 & 16.9 & 38.8 & 3.1 & 15.6 & 100.00 \\
\hline & \multirow{2}{*}{ Total } & Count & 90 & 56 & 104 & 36 & 75 & 361 \\
\hline & & $\%$ & 24.9 & 15.5 & 28.8 & 10.0 & 20.8 & 100.00 \\
\hline \multirow{6}{*}{ General scientific knowledge } & \multirow{2}{*}{ Moi } & Count & 53 & 28 & 51 & 19 & 50 & 201 \\
\hline & & $\%$ & 26.4 & 13.9 & 25.4 & 9.5 & 24.9 & 100.00 \\
\hline & \multirow{2}{*}{ Kisii } & Count & 49 & 17 & 60 & 14 & 20 & 160 \\
\hline & & $\%$ & 30.6 & 10.6 & 37.5 & 8.8 & 12.5 & 100.00 \\
\hline & \multirow{2}{*}{ Total } & Count & 102 & 45 & 111 & 33 & 70 & 361 \\
\hline & & $\%$ & 28.3 & 12.5 & 30.7 & 9.1 & 19.4 & 100.00 \\
\hline \multirow{6}{*}{ Recreation, leisure and chat } & \multirow{2}{*}{ Moi } & Count & 32 & 15 & 28 & 53 & 73 & 201 \\
\hline & & $\%$ & 15.9 & 7.5 & 13.9 & 26.4 & 36.3 & 100.00 \\
\hline & \multirow{2}{*}{ Kisii } & Count & 28 & 6 & 16 & 62 & 48 & 160 \\
\hline & & $\%$ & 17.5 & 3.8 & 10.0 & 38.8 & 30.0 & 100.00 \\
\hline & \multirow{2}{*}{ Total } & Count & 60 & 21 & 44 & 115 & 121 & 361 \\
\hline & & $\%$ & 16.6 & 5.8 & 12.2 & 31.9 & 33.5 & 100.00 \\
\hline
\end{tabular}

\subsection{What Students Learn from the Phone Internet?}

In the framework of university life, students highly use the phone internet to obtain course materials and content for their programme specialization. This finding further strengthens the points that university students learn from binary sources of lectures and the internet. Usage of the phone internet to learn course content of knowledges that are less mainstream to students' studies is low, but modest for fetching materials and content for general scientific knowledge. In addition, university students highly use phone internet for recreation, leisure and chat in their social world. These four uses together complement the lecture room learning, but the four each can be explained as intra-spaces across which students shuttle.

"Although I use the internet on my phone to learn newer things, I also use it a lot to reach out and communicate with my friends and the rest of the world on many matters, including sports betting”.

(Fourth year male student, FASS Kisii University)

Students were observed in the lecture rooms and outside. In lecture rooms, students were observed searching information related to topics of the lecture, indicating that they shift between the lecture and internet within the same lecture space. This observation largely agrees with the interview findings in the table above. Furthermore, students were observed and even photographed at times in between lectures, in the evenings at university internet hot spots and in the libraries. Observations were made of students mostly obtaining learning content in between lectures and in libraries, but mostly chatting and visiting leisure sites at internet hot spots in the evenings. Interestingly, twelve of the twenty six observations captured students chatting on WhatsApp, Facebook and Twitter and three observations made of sports betting during lecture time. University students both use the phone internet in distinct spaces outside lecture rooms for learning and also for social and leisure communication. In addition, they concurrently move back and forth between lecture and short internet sessions again for learning purposes but also for social, recreation and leisure communication.

As indicated in the table below, students use the phone internet considerably to learn while outside the lecture room (averagely $28.5 \%$ and very highly $25.5 \%$ ), and also profoundly so, they use the phone internet during lectures (averagely $33.2 \%$ and $21.1 \%$ very highly). 


\subsection{Time Students Learn Using the Internet}

Table 6. What time do you use phone internet to learn

\begin{tabular}{|c|c|c|c|c|c|c|c|c|}
\hline & & & \multicolumn{6}{|c|}{ Scale } \\
\hline Aspects & County & & Very low & Low & Average & High & Very high & Total \\
\hline \multirow{6}{*}{ Outside lecture room } & \multirow{2}{*}{ Moi } & Count & 42 & 15 & 46 & 40 & 58 & 201 \\
\hline & & $\%$ & 20.9 & 7.5 & 22.9 & 19.9 & 28.9 & 100.00 \\
\hline & \multirow{2}{*}{ Kisii } & Count & 34 & 19 & 57 & 16 & 34 & 160 \\
\hline & & $\%$ & 21.2 & 11.9 & 35.6 & 10.0 & 21.2 & 100.00 \\
\hline & \multirow{2}{*}{ Total } & Count & 76 & 34 & 103 & 56 & 92 & 361 \\
\hline & & $\%$ & 21.1 & 9.4 & 28.5 & 15.5 & 25.5 & 100.00 \\
\hline \multirow{6}{*}{ During lecture } & \multirow{2}{*}{ Moi } & Count & 51 & 23 & 50 & 29 & 48 & 201 \\
\hline & & $\%$ & 25.4 & 11.4 & 24.9 & 14.4 & 23.9 & 100.00 \\
\hline & \multirow{2}{*}{ Kisii } & Count & 35 & 18 & 70 & 9 & 28 & 160 \\
\hline & & $\%$ & 21.9 & 11.2 & 43.8 & 5.6 & 17.5 & 100.00 \\
\hline & \multirow{2}{*}{ Total } & Count & 86 & 41 & 120 & 38 & 76 & 361 \\
\hline & & $\%$ & 23.8 & 11.4 & 33.2 & 10.5 & 21.1 & 100.00 \\
\hline
\end{tabular}

\subsection{Detriment of Learning Using the Phone Internet Concurrently with Lecture}

Table 7. How detrimental is concurrency of a lecture and phone internet use

\begin{tabular}{|c|c|c|c|c|}
\hline & & \multicolumn{2}{|c|}{ University } & \multirow{2}{*}{ Total } \\
\hline & & Moi & Kisii & \\
\hline \multirow{2}{*}{ Very low } & Count & 69 & 34 & 103 \\
\hline & \% within University & $34.3 \%$ & $21.2 \%$ & $28.5 \%$ \\
\hline \multirow{2}{*}{ Low } & Count & 30 & 26 & 56 \\
\hline & \% within University & $14.9 \%$ & $16.2 \%$ & $15.5 \%$ \\
\hline \multirow{2}{*}{ Average } & Count & 37 & 53 & 90 \\
\hline & \% within University & $18.4 \%$ & $33.1 \%$ & $24.9 \%$ \\
\hline \multirow{2}{*}{ High } & Count & 22 & 12 & 34 \\
\hline & \% within University & $10.9 \%$ & $7.5 \%$ & $9.4 \%$ \\
\hline \multirow{2}{*}{ Very high } & Count & 43 & 35 & 78 \\
\hline & $\%$ within University & $21.4 \%$ & $21.9 \%$ & $21.6 \%$ \\
\hline \multirow{2}{*}{ Total } & Count & 201 & 160 & 361 \\
\hline & \% University & $100.0 \%$ & $100.0 \%$ & $100.0 \%$ \\
\hline
\end{tabular}

University students think that the detriment of using the phone internet concurrently with lectures in their learning and knowledge acquisition is low $(15.5+28.5) 44 \%$, and those who state that the effect is high are only $(9.4+21.6)$, 31\% in comparison. Observations from the study showed the comfort with which students continued to search information relating to the topic of study to reinforce the lectures and how they passionately engaged with their phones and lap tops at the internet hot spots in the evenings after the lecture. Despite the benefits, there is indication that internet use can be disruptive, as reported in the following quote:

"Sometimes I switch to the internet, in the middle of other activities, even during lectures, and this makes me loose tract”. 
Table 8. How beneficial is concurrency of a lecture and phone internet use?

\begin{tabular}{|c|c|c|c|c|}
\hline & & \multicolumn{2}{|c|}{ University } & \multirow{2}{*}{ Total } \\
\hline & & Moi & Kisii & \\
\hline \multirow{2}{*}{ Very low } & Count & 12 & 48 & 60 \\
\hline & \% within University & $6.0 \%$ & $30.0 \%$ & $16.6 \%$ \\
\hline \multirow{2}{*}{ Low } & Count & 14 & 18 & 32 \\
\hline & \% within University & $7.0 \%$ & $11.2 \%$ & $8.9 \%$ \\
\hline \multirow{2}{*}{ Average } & Count & 30 & 55 & 85 \\
\hline & \% within University & $14.9 \%$ & $34.4 \%$ & $23.5 \%$ \\
\hline \multirow{2}{*}{ High } & Count & 51 & 10 & 61 \\
\hline & \% within University & $25.4 \%$ & $6.2 \%$ & $16.9 \%$ \\
\hline \multirow{2}{*}{ Very high } & Count & 94 & 29 & 123 \\
\hline & \% within University & $46.8 \%$ & $18.1 \%$ & $34.1 \%$ \\
\hline \multirow{2}{*}{ Total } & Count & 201 & 160 & 361 \\
\hline & \% within University & $100.0 \%$ & $100.0 \%$ & $100.0 \%$ \\
\hline
\end{tabular}

\subsection{Benefit of Learning Using the Phone Internet Concurrently with Lecture}

To further ascertain the point, students were asked how beneficial was concurrency of lecture and phone internet use, and $(16.9+34.1) 51 \%$ affirmed that the concurrent use was highly beneficial to their learning and knowledge acquisition, while only $(16.6+8.9) 25.5 \%$ indicated it was low. Asked further what were the benefits, students reported the following that;

When I visit the internet on my phone during class, I am able to clarify concepts the lecturer is using, without having to interrupt the class....some lectures are shallow, so I Google to add more details either in class or in the evening,......some lecturers are so fast, and instead of trying to write everything, I write bullets and in the evening I expand the notes using Google.

(Third year female student, SASS Moi University)

\subsection{Space and Phone Internet Use}

Table 9. Chi-Square Test

\begin{tabular}{|c|c|c|c|}
\hline & Value & df & $\begin{array}{c}\text { Asymp. Sig. } \\
\text { (2-sided) }\end{array}$ \\
\hline Pearson Chi-Square & 564.214 & 480 & .005 \\
\hline Likelihood Ratio & 507.411 & 480 & .187 \\
\hline N of Valid Cases & 361 & & \\
\hline
\end{tabular}

Pearson's statistical test shows that spaces university students reside in, significantly influence internet usage (chi square p-value $=.005$ ). In addition, the likelihood ratio shows that environments students are found in are more than two times likely to influence phone internet use by students (likelihood ratio $=.187$ ). University students use the phone internet depending on the spaces they are situated in. during the lecture hour, students use the internet to add information and clarify knowledge content of the lecture. In between lectures, and in the evenings students use the internet for the same reasons, but also to make notes of the lectures and also for leisure, recreation, chat and sports, thus with social communication unrelated to the learning process. This finding reinforces the argument that university students reside in varied spaces shuttling between the real world of academic knowledge acquisition in lecture rooms and virtual space on the internet for knowledge gain and also for social communication.

\section{Discussion}

The analysis of this transformation, promulgates the need to change the narrative that is still dominant in university learning processes and definitions of spaces the university student resides in [13, 23, 24]. This claim arises because there are serious doubts whether the approach most widely used teaching and learning in universities, focusing on the lecture suffices or not [24]. Findings show how it is beneficial if the lecture knowledge is augmented by individual internet searches of knowledge. Whether this diversion to add knowledge is spontaneous and guided is a research question for another day. Notwithstanding, this added avenue seems to develop fast in students' career trajectories. This situation has promoted interest in improving knowledge gain and perhaps academic performance, especially where lecture resources and capacities seem to be dwindling and not improving in Kenyan public universities, where the study drew its sample. The benefit of concurrent and multiple sources of knowledge at the university has been studied, and this particular research findings add voice to the need to standardize and add credibility to the initiatives students take to gain knowledge in different spaces in their learning and social lives. Such initiatives should be recognized in Kenya, and made better by Kenyan universities by revision 
of teaching-learning policies at universities, aimed specifically at promoting their integration into the working world. In this scenario, we observe and recognize the two communities in which the $21^{\text {st }}$ Century Kenyan university student resides and translocate to learn and socialize[4]. Various scholars have stated the importance of shifting in spaces strategically using contemporary technologies such as the phone, media and internet in order to gain knowledge and learn [5], in what has been phrased elsewhere as multiple literacies and multimodality. More researchers in this field have applauded the multiple sources of learning spaces with references such as 'hybridization' and 'intercultural' [12]. Anthropologist Clifford Geertz [14, 15], argued that the holistic nature of the phenomenon is more advantageous in ethnographies. This paper draws out the benefit of multiple and holistic sources of learning by exploring what many learning space communities a university student can translocate in, in order to learn. According to Geertz [15], "crossing disputed borders". The paper further argues that flexible and open approach offers emergencies of practice. The conceived multidimensional learning spaces restate the voice of young people in Kenya over how best they learn, and how learning can take place in various spaces not necessarily in designated lecture spaces.

\section{Conclusions}

The paper highlights the benefits of translocated multiple learning spaces the university student in Kenya, shuttles in. Ethnographies have been a domain of physically identified communities of the world, but here the paper joins an emerging trend to study virtual communities and spot out their virtual residence as a reality and not illusionary. It is not a surprise when young generations are always on the phone set today in universities and other communities, after all, this is "their new home", and researchers should follow and study them in their new locations. The paper recommends that the internet is a new and more exciting way the youth are learning and there is need to observe this source of learning and socializing, to be able to recognize and standardize the virtual space that the youth domicile. Importantly, to understand better the characteristics of the human youth as they pilgrimage and operate in these newer spaces. After all, learning and social interaction transforms using emerging technologies.

\section{REFERENCES}

[1] Good L.T. (ed) (2008). $21^{\text {st }}$ Century Education: A reference handbook. New York, SAGE Publications, Inc.

[2] Singh R.R. (1991). Education for the twenty-first century:
Asia-Pacific perspectives. UNESCO Regional Office for Asia and the Pacific, Bangkok, 1991.

[3] Krejcie R.V., \& Morgan D.W. (1970). Determining sample size for research activities: Educational and Psychological Measurement, Vol. 30, pp. 607-610.

[4] OECD (2000), the Creative Society of the 21st Century, Paris.

[5] Three ways technology supports learning in the $21^{\text {st }} \mathrm{C}$; https://echo360.com/technology-supports-21st-century-stu dents/; Accessed on $27^{\text {th }}$ July 2018.

[6] Button G. (2000). The ethnographic tradition and design: Design Studies, Vol. 21(4), pp. 319-332.

[7] Pina-Cabral J. (2011). Ethnography as tradition in Africa: Etnografica, Vol. 15(2), pp. 379-394.

[8] Malinowski B. (1967). Argonauts of the Western Pacific. London, Routledge.

[9] Durkheim E. (1957). Suicide. London, Lowe and Brydone.

[10] Anderson R.J. (1996). Work, ethnography and system design: The Encyclopaedia of Micro Computing.

[11] Appadurai A. (1990). Disjuncture and difference in the global cultural economy. Theory, Culture \& Society, Vol. 7(2-3), pp. 295-310.

[12] Canclini, G.N. (2011). La sociedad sin relato: antropologia estetica de la inminencia, Revista Austral de Ciencias Sociales, Vol. 20, pp. 135-137.

[13] Hargreaves A. (1994). Changing teachers, changing times: Teachers' work and culture in the postmodern age. Toronto: University of Toronto Press.

[14] Geertz C. (1988).The Interpretation of Cultures. Barcelona: Gedisa.

[15] Geertz C. (1973).The Interpretation of Cultures: Selected Essays by Clifford Geertz. New York, Basic Books, Inc., Publishers.

[16] Mayring P. (2014). Qualitative Content Analysis: Theoretical foundation, basic procedures and software solution. Auckland, Auckland University of Technology.

[17] National Commission for the Protection of Human Subjects of Biomedical and Behavioral Research: The Belmont Report, 1979.

[18] Greenwood D.J. (2000). Theory-Practice Relations in Anthropology: A commentary and Further Provocation: NAPA Bulletin, Vol. 18(1), pp. 164-175.

[19] Freilich M. (1970). Marginal Natives: Anthropologist at work. New York: Harper \& Row.

[20] Barley N. (1989). El Antropólogoinocente. Barcelona: Editorial Anagrama.

[21] Hammersley M., \& P. Atkinson. (1994). Etnografía. Métodos de Investigación. Barcelona: Paidós.

[22] Hine, C. (2000). Virtual Ethnography, London: Sage Publications.

[23] Hakken 1999 (1999b) Cyborgs@cyberspace? An 
Ethnographer looks to the future. New York, Routledge.

[24] Birbili M. (2005). Constants and contexts in pupil experience of schooling in England, France and Denmark: European Educational Research Journal, Vol 4(3), pp. 313-320.

[25] Lankshear C., \& Knobel M. (2008). New Literacies: Changing knowledge and classroom learning. New York: McGraw-Hill. 